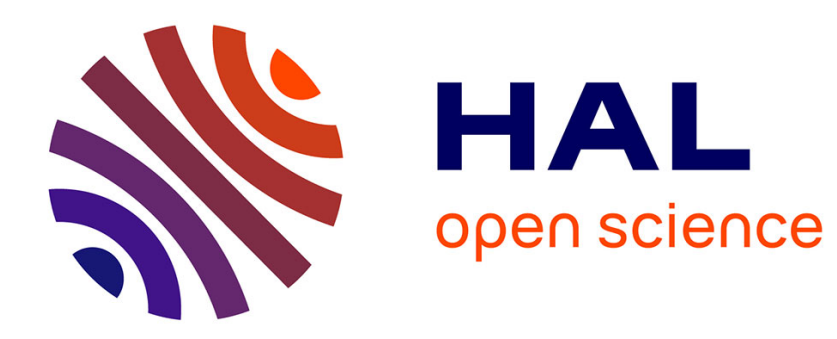

\title{
Cauchy and Puiseux: Two precursors of Riemann Athanase Papadopoulos
}

\section{To cite this version:}

Athanase Papadopoulos. Cauchy and Puiseux: Two precursors of Riemann. L.Ji, A. Papadopoulos and S. Yamada. From Riemann to differential geometry and relativity, Springer, 2017, 10.1007/9783-319-60039-0_7 . hal-01674509

\section{HAL Id: hal-01674509 \\ https://hal.science/hal-01674509}

Submitted on 3 Jan 2018

HAL is a multi-disciplinary open access archive for the deposit and dissemination of scientific research documents, whether they are published or not. The documents may come from teaching and research institutions in France or abroad, or from public or private research centers.
L'archive ouverte pluridisciplinaire HAL, est destinée au dépôt et à la diffusion de documents scientifiques de niveau recherche, publiés ou non, émanant des établissements d'enseignement et de recherche français ou étrangers, des laboratoires publics ou privés. 


\title{
CAUCHY AND PUISEUX: TWO PRECURSORS OF RIEMANN
}

\author{
ATHANASE PAPADOPOULOS
}

\begin{abstract}
We review the works of Cauchy and Puiseux on the theory of functions of a complex variable that preceded Riemann's introduction of what soon became known as Riemann surfaces. The work of the two French mathematicians (especially that of Puiseux) inaugurates a group-theoretic point of view which complements the topological one discovered by Riemann.

The final version of this paper appears as a chapter in the book From Riemann to differential geometry and relativity (L. Ji, A. Papadopoulos and S. Yamada, ed.) Berlin: Springer, 647 p., 2017.
\end{abstract}

AMS Mathematics Subject Classification: 30F10, 30F20, 01A55

Keywords: Riemann surface, algebraic function, multi-valued function, uniformization, monodromy.

\section{Contents}

1. Introduction

2. Algebraic functions and uniformization 2

3. Puiseux and uniformization 3

4. Cauchy and his work on functions of a complex variable 10

5. Uniformization again 19

$\begin{array}{ll}\text { References } & 21\end{array}$

\section{InTRODUCTION}

Riemann surfaces were introduced unexpectedly by Riemann in his doctoral thesis, defended on December 16, 1851. I said "unexpectedly" because it was something completely new, difficult to apprehend by Riemann's contemporaries, and it is not clear whether somebody else would have invented this notion even fifty years after Riemann, had he failed to do it. Riemann introduced these surfaces as ground spaces on which holomorphic (or meromorphic) functions are naturally defined. We recall Klein's sentence from his monograph [41] in which he surveys Riemann's ideas (p. 77): "The Riemann surface not only provides an intuitive illustration of the functions in question, but it actually defines them." In particular, a multi-valued function given as the solution of an algebraic equation acquires a new domain of definition, its associated Riemann surfaces, on which it becomes uniform (single-valued). This idea of working with general surfaces equipped with complex structures, instead of only the sphere or the complex plane, or subsets of them, had a tremendous influence on the development of complex analysis, but also on geometry and topology.

The notion of Riemann surface, as all mathematical notions, has a history. Its discovery was motivated by several questions on which many mathematicians spent their lives. One of the main problems that led to this notion was addressed by the uniformization of algebraic functions. In fact, the notion of "algebraic function"

Date: January 3, 2018. 
is complicated, because such a "function" is generally not a function in the usual sense: it is multi-valued. In this sense, the uniformization problem asks for a way of getting around this complication. It is in trying to solve this "uniformization problem" that the theory of Riemann surfaces was born.

In this chapter, I will explain how the problem of uniformization of algebraic functions led to results by Puiseux - who was strongly motivated by the work of Cauchy - which, interpreted in the right perspective, are the algebraic counterpart of Riemann surfaces. The work of Puiseux, rather than the one of Riemann, was discussed in the French treatises on analysis during the first decades that followed these works. We discuss this fact in Chapter 8 of the present volume [51].

The outline of the rest of this chapter is the following.

In Section 2 we recall the notion of algebraic function and the problem of uniformization of such functions.

Section 3 is the heart of the chapter. We explain there how Puiseux, in his two articles published in 1850 and 1851, using Cauchy's theory of path integration, developed a notion which is a combinatorial analogue of the notion of Riemann surface. Puiseux's theory was also rooted in the theory of the uniformization of algebraic functions, and it makes connections with group theory, in particular with Galois theory. This section also contains information on the life of Puiseux.

In Section 4, we give a summary of the important work of Cauchy that was used by Puiseux when he developed his theory. This work was also available to Riemann when he introduced Riemann surfaces.

In Section 5, we review Hilbert's 22nd problem which concerns uniformization. In this statement, the word uniformization is slightly different from the one we use in the previous sections, but the two notions are closely related, and the origin of the two words is the same. Our goal in this concluding section is to indicate the development of the theory whose bases were laid down by Puiseux and Riemann.

\section{Algebraic Functions And Uniformization}

An algebraic function $u$ of the complex variable $z$ is defined by an equation

$$
f(u, z)=0
$$

where $f$ is a polynomial in the two variables $u$ and $z$. Here, $u$ is considered as an implicitly defined function of $z$. For each value of $z$, there are generally more than one value of $u$. (If the equation is irreducible, then the number of values is the highest degree of $u$ in the equation.) The first question that arises is: Can one make a choice between these values so as to get a bona fide function $u(z)$ ? The obvious answer is clearly "no," but one wishes to understand more. The first approach to the question is a case by case analysis. Consider for example the case where $f$ is the polynomial $f(u, z)=u^{2}-z$. Then, for each value of $z$, we have, except if $z=0$, two different values of $u$. Setting $z=r e^{i \theta}$ with $r>0$, the two values are $u_{1}=\sqrt{r} e^{i \theta / 2}$ and $u_{2}=-\sqrt{r} e^{i \theta / 2}$. If for some value of $z$ we choose one of the values $u_{1}$ or $u_{2}$ and assign it to $u(z)$, and if we try to extend $u$ as a function defined on the whole complex plane, we obtain a discontinuous function, which is not desirable. We are then led to define the function $u(z)$ on a subset of the plane, but there is no natural choice of such a subset.

Uniformization originates with this problem, that is, the fact that algebraic equations generally have more than one complex solution. The word "uniformization", in the sense of Riemann, refers to the fact that one would like to have a way of making such a multi-valued function single-valued, or "uniform." The German adjectives einwerthig and mehrwerthig used by Riemann are translated, in the 1898 French version [66], by uniforme and multiforme. In the recent English translation 
by Jason Ross, the same words are used: uniform and multiform. Riemann utilises the word mehrwerthig (multiform) for a function which may assign to a value of the variable more than one value, and einwerthig (uniform) otherwise. In the preliminary part $(\S \mathrm{I})$ of his memoir on Abelian functions, he addresses the problem of extending a holomorphic function defined on a piece of the plane. He writes: "From the nature of the function we wish to extend, this function either will always take, or will not take, the same value for a given value of $z$ regardless of the path along which we are extending. In the first case, I will call it uniform: it is then a perfectly determined function for any value of $z$, and it will never be discontinuous along a line. In the second case, where we shall say it is multiform, we first have, in order to understand the motion of this function, to concentrate our attention on certain points of the $z$-plane, around which the function is extended into another function..." A little bit later, he uses, as an alternative for the word "uniform," the word "monodromic" (see our Footnote 10). Likewise, in his memoir [64], Riemann uses the word monodromic as a synonym for uniform. Weyl, in [73] (p. 2), also uses the word "uniform." We shall use the word "uniformization" in this original sense of Riemann. There are other meanings for the word uniformization; see $\S 5$ of the present paper.

The modern definition of function assumes that a function is single-valued, or "uniform," that is, to each value of the variable, the function associates a single value. But this was not the case at the epoch of Riemann or Cauchy or before them. In fact, Euler, to whom the first abstract definition of a function is attributed, considered the possibility that a function is multi-valued. Riemann was a devoted reader of Euler. He mentions his name at several occasions, when he informs his reader about the origin of his own ideas, for instance in his doctoral dissertation, in his Habilitation dissertation [61], in his memoir on Gauss's hypergeometric series [64], and there are several references to Euler in Riemann's memoirs and posthumous papers. The interested reader may find a thorough report on Riemann's debt to Euler in Chapter 1 of the present volume [49]. Among other things, we discuss in that chapter the way the notions of algebraic and multivalued functions appear in Euler's treatise Introductio in analysin infinitorum (Introduction to the analysis of the infinite) (1784) [29].

\section{Puiseux AND Uniformization}

Victor Puiseux (1820-1883) defended a doctoral dissertation on astronomy in 1841. He attended Cauchy's courses on analysis and soon became interested in this topic. At the same time, he became Cauchy's closest follower and friend, and he always expressed his respect and admiration for his teacher's work. Puiseux spent a large part of his time developing, correcting and refining results of Cauchy who used to publish very rapidly his ideas, sometimes in rough form. Cauchy's influence on Puiseux was enormous.

Motivated by Cauchy's work, Puiseux wrote two remarkable memoirs, Recherches sur les fonctions algébriques (Researches on algebraic functions, 1850) [57] and Nouvelles recherches sur les fonctions algébriques (New researches on algebraic functions, 1851) [58]. The second memoir appeared in the year Riemann defended his doctoral dissertation, consisting of his first memoir on the theory of functions of a complex variable. ${ }^{1}$ After the publication of Riemann's dissertation, Puiseux practically stopped working on this topic.

Below, we shall give a quick review of the content of the two memoirs of Puiseux.

\footnotetext{
${ }^{1}$ It may be useful to recall that Dedekind, in his notes on Riemann's life published in the Collected works edition [65], states that Riemann probably conceived his ideas on Riemann surfaces in 1847.
} 
Puiseux taught mathematics at the École Normale Supérieure. From 1855 to 1859, he worked at the Observatory of Paris, and in 1859 he became a member of the Bureau des longitudes. ${ }^{2}$ In 1857, he became the successor of Cauchy on the chair of astronomy at the University of Paris, and he taught there until his health became critical, in 1882, one year before his death. His works included, besides complex analysis, mechanics, observational astronomy and botanics. Puiseux also made important contributions to celestial mechanics. In this field, he solved several difficult questions which had also been addressed by Cauchy. One of his most influential memoirs in this domain is the Mémoire sur l'accélération séculaire du mouvement de la lune (Memoir on the secular acceleration of the motion of the moon) [59] 1873, in which he contributed to the difficult problem of explaining the acceleration of the mean motion of the moon. Puiseux is also a precursor of French Alpinism, and a pick (3946 m) in the Alps, which he climbed in 1848, carries his name.

We shall give in the next section several biographical details on Cauchy. Let us mention that like Cauchy, Puiseux was involved in social issues, that he founded several charities, including one for the help of the poor at their home. During his lifetime, Puiseux kept secret most of his philanthropical activity, which was discovered by his family only after his death [?]. Picard writes about Puiseux as a teacher $\left([53]\right.$ p. v): ${ }^{3}$ :

Victor Puiseux's modesty was intimidating, and his patience and politeness were admirable. To a student blundering at some test, he just used to say, with a very sweet tone: "I don't know whether I heard well or whether I am mistaken, but it seems to me that what you said is not completely true." 4

In an article [57] published in 1850, that is, one year before Riemann defended his doctoral thesis, Puiseux addressed the problem of uniformization. As a result, he did not introduce Riemann surfaces, but he discovered a notion which is close to it. We now give a short description of his work on the subject, using the notation of $\S 2$ above for an algebraic function, which is Puiseux's notation.

Puiseux writes, after introducing the discontinuity problem posed by multivalued functions which we recalled in the introduction ([57] p. 366):

We shall avoid this discontinuity by defining in a different way the function $u$. Let us consider again the equation

$$
f(u, z)=0,
$$

of which we may assume the first side to be integral in $u$ and $z$; let us give to $z$ an arbitrary initial value $c$, and, for the initial value $b$ of $u$, let us choose any one of the solutions of the equation

$$
f(u, c)=0 .
$$

Let us now conceive that $z$ varies in an arbitrary manner starting from the value $c$, and reaches another value $k$. M. Cauchy showed (Nouveaux Exercices de Mathématiques, tome II, p. 109) that the different values of $u$ vary simultaneously in a continuous manner. Thus, there will be one which is first equal to $b$, which will pass by infinitely small steps to a determinate value $h$ which it will attain for $z=k$. For us, this value

\footnotetext{
${ }^{2}$ The Bureau des longitudes is a French institution in charge of geodesy, standardisation of time-keeping, and astronomical measurements. The names of famous members of the Bureau include Lagrange, Laplace and Poincaré.

${ }^{3}$ In this chapter, all the translations from the French are mine.

${ }^{4}$ Victor Puiseux était d'une modestie intimidante, d'une patience et d'une politesse admirables. Quand un élève avait, dans une interrogation, énoncé quelque énormité, il se contentait de lui dire d'un ton très doux "Je ne sais pas si j'ai bien entendu ou si je me trompe, mais il me semble que ce que vous avez dit n'est pas tout à fait exact."
} 
of $u$ will be a function of $z$, and, as we can see, it will be a continuous function. But its determination, for a particular value of $z$, will depend at the same time on this same value and on the series of values by which $e$ passed starting from its initial value.

Thus, Puiseux solves the continuity problem by declaring that the function $u(z)$ not only depends on the variable $z$ but also on a path that we choose from a basepoint to the point $z$. Concerning the choice of the path, he writes:

Let us observe however that the function will stop being determined if, when passing from the value $c$ to the value $k, z$ takes a value for which the equation

$$
f(u, z)=0
$$

have equal solutions. But the number of these values being finite, it will always be possible to avoid this circumstance, for any values $c$ and $k$.

Thus, the chosen path between the basepoint and this point $z$ avoids a certain number of singular points. Puiseux investigates in detail the dependence of $u(z)$ on the path, highlighting the roles of the singular points, which, he says, are of two types: points where the function $u$ becomes infinite, and points which correspond to multiple solutions of the algebraic equation. Cauchy, in his previous works, misunderstood the nature of the singularities, since he considered that the singular points are only those where the algebraic function $u$ becomes infinite. Puiseux presents clearly the invariance of the value of the function at the point $z$ under homotopy of paths.

To show the close relation with Riemann's work, we need to recall Riemann's idea of a Riemann surface, and we consider again the example of the algebraic function $w^{2}-z=0$. In this case, $w$ is the "function" $\sqrt{z}$. We take a basepoint $z_{0} \neq 0$ in the complex plane. The function $\sqrt{z}$ is multi-valued at such a point. We take some determination of this function in some neighborhood of $z_{0}$. We continue the definition of this function along paths starting at $z_{0}$ (we use analytic continuation). We allow ourselves the use of modern terminology. A problem arises when the path comes back at $z_{0}$ and encloses the origin 0 of the complex plane. If such a path is not simple (that is, injective), the fact of enclosing the origin means that it has non-zero winding number with respect to 0 . If such a path has odd winding number with respect to the origin, the value we get at $z_{0}$ is different from the initial one. At this point, Riemann introduced the idea that in this case the endpoint of such a path should not be considered as the basepoint $z_{0}$, but a point on a different sheet of a new surface on which the function $\sqrt{z}$ should be defined. This is the Riemann surface associated with the function. At the same time, Riemann introduced the notion of covering space. In the example considered, the surface obtained is a two-sheeted branched cover of the complex plane (or of the sphere), and the branching locus is the origin. This construction is very general, that is, it associates to an arbitrary multi-valued function defined by an algebraic equation a Riemann surface which is a branched cover of the sphere and on which the function is defined and becomes single-valued. The degree of the covering is the number of values of $w$ associated with a generic value of $z$. This construction is described for the first time in Riemann's dissertation [60] and is further developed in the section on preliminaries in his 1857 paper [62].

It is not hard for a topologist to see that Puiseux's description of $u$ as a function, not of $z$ alone, but of a pair $(z, \gamma)$, where $\gamma$ a homotopy class of paths joining a basepoint to the variable point $z$, the homotopy being relative to some finite set of points on the surface (namely, the set of singular points of the algebraic equation $f(z)=0$ ), is equivalent to considering that the function is defined on a Riemann surface which is a covering of the complex plane, ramified over this set of singular 
points. In fact, the usual modern construction of a covering of a surface defines it as a set of equivalence classes of homotopy classes of paths in the base surface subject to certain conditions which can be expressed in terms of group theory. (With no condition on the homotopy classes of paths, we get the universal covering of the base surface.) Let us emphasize though that we know the relation between the two definitions, the one of Puiseux and the one using Riemann surfaces and their coverings, initiated by Riemann, because we are familiar with the theory of surfaces. Thus, we are not claiming that Puiseux discovered Riemann surfaces. But he came very close to them. In fact, the work of Puiseux is group-theoretic, before the formal introduction of groups in the theory of Riemann surfaces. There is a famous result due to Riemann, which he gives in his paper on Abelian functions [62]. The result, stated in modern terms, says that given a finite set of points on the Riemann sphere and a representation of the fundamental group of the complement of these points into a permutation group, there exists a Riemann surface which is a branched covering of the sphere having the given points as branch points and whose monodromy is the given representation. This is one form of the so-called Riemann existence theorem (there are several other forms). The general form of the theorem deals with branched covers of surfaces that are more general than the Riemann sphere. The theorem establishes relations between topology, group theory and function theory. The permutation representation is that which Puiseux studies.

It was natural that Puiseux, in considering functions defined using paths from a basepoint to the variable point, studies line (or path) integrals, especially that the theory of such integrals was part of Cauchy's courses he followed. Starting from $\S 8$ of his memoir [57], Puiseux considers line integrals of the form $\int_{c}^{k} u d z$ where $c$ and $k$ are points in the complex plane. In $\S 9$ (p. 373), he proves the following theorem:

The value of the integral $\int_{c}^{k} u d z$, taken along the line $C M K$, will not change if, the points $c$ and $k$ remaining fixed, this line is deformed without crossing any point for which the function $u_{1}$ becomes infinite or equal to another solution of the equation $f(u, z)=0 .^{5}$

(Here, $u_{1}$ is a fonction obtained by starting with one of the branches of the function $u$ defined by the equation $f(u, z)=0$.)

Puiseux attributes this theorem to Cauchy, like a few others he proves in $\S 9$ to 11 of his memoir, as preliminaries for his main results. However, he brings important complements to Cauchy's results. He states ([57] Note p. 375):

The theorems in $\S 9,10,11$ were given by Mr. Cauchy in the Comptes Rendus des séances de l'Académie des Sciences, year 1846. But the famous geometer [Cauchy] characterizes the points which must be avoided by the path that is travelled by the fact that at these points the function becomes discontinuous; but since I restrict here to algebraic functions, I thought I would give more precision to the statements and the proofs by saying that the points considered are those for which the function $u$ either becomes infinite or is a multiple solution of the equation $f(u, z)=0 .^{6}$

Later in the same paper ( $\$ 53$ to 55$)$, Puiseux considers elliptic integrals and their dependence on the integration path, and he makes explicit the periods of the

\footnotetext{
${ }^{5}$ L'intégrale $\int_{c}^{k} u d z$, , prise le long de la ligne $C M K$, ne changera pas de valeur, si, les points $C$ et $K$ restant fixes, cette ligne vient à se déformer, sans franchir toutefois aucun point pour lequel la fonction $u_{1}$ devient infinie ou égale à une autre racine de l'équation $f(u, z)=0$.

${ }^{6}$ Les théorèmes de nos 9, 10, 11 ont été donnés par M. Cauchy dans les Comptes Rendus des séances de l'Académie des Sciences, année 1846. Seulement l'illustre géomètre caractérise les points que le chemin parcouru ne doit pas franchir en disant que, pour ces points, la fonction devient discontinue : comme je me borne ici aux fonctions algébriques, j'ai cru donner plus de précision aux énoncés et aux démonstrations en disant que les points dont il s'agit sont ceux pour lesquels la fonction $u$ devient infinie ou une racine multiple de l'équation $f(u, z)=0$.
} 
inverse functions. We note incidentally that the study of these integrals was one of the main subjects of interest of Riemann. We shall consider this question again below.

In the second part of his memoir [57] (starting p. 384), Puiseux studies the passage from one value of $u$ to another one corresponding to the same $z$. This involves a detailed analysis of how the various values $u_{1}, \ldots, u_{p}$ corresponding to a given $z$ are interchanged when the point $z$, seen as a geometric point in the complex plane, describes a small loop. The result will depend on the behavior of the function at the singular points enclosed by the loop.

Puiseux discovered the fact that the solutions of an algebraic equation are grouped into cycles which he called circular systems (systèmes circulaires) and he gave a method to perform this grouping. This decomposition into circular systems is related to the fact that the solutions are permuted by following the points geometrically along closed paths, and that an arbitrary permutation may be decomposed into circular permutations, a fact already proved by Cauchy in his paper [16], precisely in the setting of solutions of algebraic equations. In p. 479 of his memoir [57], he writes that the possibility of grouping into circular systems the various solutions $u_{1}, u_{2}, \ldots$ and of seeing that these values are interchanged around the points where the function $u$ has multiplicity or takes the value infinity may be deduced from a theorem on substitutions ${ }^{7}$ by Cauchy (Journal de l'École Polytechnique, tome $\mathrm{X}$ ). But he adds that the method that he gives for this grouping is new.

The third part of the memoir [57] concerns applications of the theory to periods of integrals. Again, Puiseux refers to Cauchy's work, declaring that it leads to the existence of periods, that Cauchy recovered in this way the periods of elliptic integrals, but that Cauchy's method does not allow one to recover periods of general integrals. With his results on periods, Puiseux gave an explanation of the periodicity in the determinations of the complex circular functions, of elliptic functions and of other functions defined by integrals (in particular those introduced by Jacobi).

On p. 428 of his memoir, Puiseux says that the propositions he established are also applicable to the case where the function $u$ of the variable $z$, which was taken to satisfy an algebraic equation $f(u, z)=0$, is transcendental instead of being algebraic. He declares that the only property that is used is the continuity of $u$ in terms of $z$, and he says that this question was treated by Cauchy in his Nouveaux Exercices de Mathématiques, tome II, p. 109.

In the following year, Puiseux published a second paper [58] in which he gave a method for characterizing periods of integrals in the case where the function $f$ in the equation $f(u, z)=0$ is an irreducible polynomial.

Puiseux's paper [57] also contains the so-called "Newton-Puiseux polygon," a method for evaluating the value of an algebraic function near a branch point, using so-called Pusieux series. These are a generalization of power series where the exponent may be fractional or negative. In fact, Puiseux did not discover these series, he rather rediscovered them ([57] p. 399), since they were introduced before him by Newton, in $1676 .{ }^{8}$ Puiseux came up with these series in the context of his work on separating the various branches of functions defined by algebraic equations. He gave an expansion of each of these branches in such a convergent series. The socalled Newton-Puiseux theorem states that an algebraic equation $f(u, z)=0$, the variable $u$, seen as a function of $z$, may be expanded as a series (called now Puiseux series) that converges in some neighborhood of the origin. Stated differently, the

\footnotetext{
7In this context, a "substitution" means a permutation of letters. This word substitution is used e.g. in Jordan's Traité des substitutions et des équations algébriques [40].

${ }^{8}$ Isaac Newton, Letter to Oldenburg, October 24, 1676.
} 
result says that any branch of an algebraic curve can be represented as a Puiseux series. The Newton-Puiseux series has a wide generalization to the study of polynomials over local fields (the classical case being the one where the local field is the field of Laurent polynomials).

The work of Puiseux on solutions of algebraic equations was a forerunner of works of several mathematicians. It was interpreted and generalized in the setting of groups by Hermite and others. One should mention here that group theory was still unborn, or at best, was only in its infancy. ${ }^{9}$

Hermite presented a paper, in 1849, entitled Sur la théorie des fonctions elliptiques (On the theory of elliptic functions) [36] where he studies periods of elliptic integrals, and in which he acknowledges Cauchy's influence. We shall soon talk about the work of Hermite in relation with that of Puiseux.

We showed that Puiseux studied how the fact that the roots of an algebraic equation are interchanged when the variable $z$ describes some loops in the plane leads to a group factorized into permutations. He used in this context the word "monodromic," which was already introduced by Cauchy. Hermite continued using this word in [37] (1851). ${ }^{10}$ This led eventually to the notion of monodromy group, which we still use today. Jordan, in his Traité des substitutions [40] (1870), defined a group he called the algebraic group, which contains the monodromy group as a normal subgroup. The paper [37] by Hermite in which he studies the solvability of equations by radicals makes the relation between the work of Puiseux and the Galois group of an algebraic equation. Hermite's paper starts as follows:

It seems to me that the propositions given by Mr. Puiseux, on the roots of algebraic equations considered as functions of a variable $z$ which enters rationally in their first member, open up a wide research field which is intended to shed light on the analytic nature of this kind of quantities. I propose to give here the principle of these researches, and to show how they lead to the knowledge of whether an arbitrary equation

$$
F(u, z)=0
$$

is algebraically solvable, that is, whether the unknown $u$ can be expressed by a function of the variable $z$, containing only this variable under root extraction signs of integer degree. The theorems to which we will be led in this way will give, from a completely new point of view, the beautiful result obtained by Abel on the possibility of expressing algebraically ${ }^{11}$ $\sin \operatorname{am}\left(\frac{x}{n}\right)$ by $\sin \operatorname{am}(x)$. I restrict myself here to the question of the resolution by radicals. Later, I will show how the theorems of Mr. Puiseux lead to a lowering of these equations in the cases announced by Galois, whose principles will serve as a basis for everything we shall say. ${ }^{12}$

\footnotetext{
${ }^{9}$ It is usually considered that the first abstract definition of a group is contained in the 1854 paper by Arthur Cayley [24]. But the notion of group appears in essence, as a group of permutations of the roots of an algebraic equation, in works of various people on the solutions of polynomial equations of degree $\geq 4$, in particular the work of Galois. Klein writes, in his Development of mathematics in the 19th century ([43] p. 316 of the English translation), that "group theory first developed in the theory of algebraic equations [...] the central significance of group theory for algebraic equations first appeared in the work of Galois in 1831 (from whom the term 'group' also stems)."

${ }^{10}$ Let us note that Riemann used the word "monodromic" in his memoir on Abelian functions [62] for a function which is uniform, or single-valued. He writes ( 1 1): "To simplify the designation of these relations, we shall call the various extensions of one function, for some fixed portion of the plane of the $z$, the branches of this function, and a point around which a branch of the function extends in another one a ramification point of the function. Everywhere where there is no ramification, the function will be monodromic or uniform."

${ }^{11}$ The notation am is used in the theory of elliptic functions. It denotes the Jacobi amplitude.

${ }^{12}$ Les propositions données par M. Puiseux, sur les racines des équations algébriques considérées comme fonctions d'une variable $z$, qui entre rationnellement dans leur premier membre,
} 
Cauchy published two reports ([20] and [21]) on the two memoirs of Puiseux. In the first report, he reviews in detail his own work on the subject, and then presents Puiseux's contribution. He writes in his conclusion:

Not only Mr Puiseux added new developments and new improvements to the theory of curvilinear integrals of algebraic functions, but, furthermore, he highlighted, with a lot of wisdom, the rules according to which the various values of an algebraic function are interchanged when the curve which conducts the integration winds around one of the points he calls principal points. Finally, he was able to determine in general the number of distinct values and the periods of certain curvilinear integrals which are relative to a very large class of algebraic functions and which contain as particular cases elliptic and Abelian integrals. ${ }^{13}$

In the report on the second memoir, Cauchy mentions Puiseux's new results on the periods of curvilinear integrals and the use that Hermite made of Puiseux's results in his research on the solvability of equations by radicals.

The work of Puiseux was acknowledged as important by many mathematicians. Bertrand, ${ }^{14}$ in his eulogy of Puiseux [6] , writes the following:

Ch. Sturm, ${ }^{15}$ our benevolent master of all, but above all proud of his pupil of Collège Rollin, accosted me one day with this question which nobody before Puiseux had addressed: "If you follow along a closed loop the root of an equation whose parameter represents a point of the contour, what do you obtain when you come back to the starting point?" - I responded without hesitation: "I will recover my root." - "Well, no! you will not recover it: Puiseux proves this. He did a beautiful memoir!" 16

me semblent ouvrir un vaste champ de recherches destinées à jeter un grand jour sur la nature analytique de ce genre de quantités. Je me propose de donner ici le principe de ces recherches, et de faire voir comment elles conduisent à reconnaître si une équation quelconque

$$
F(u, z)=0
$$

est résoluble algébriquement, c'est-à-dire si l'inconnue $u$ peut être exprimée par une fonction de la variable $z$, ne contenant cette variable que sous les signes d'extraction de racines de degré entier. Les théorèmes auxquels nous serons ainsi amenés donneront, et sous un point de vue entièrement nouveau, le beau résultat obtenu par Abel sur la possibilité d'exprimer algébriquement $\sin \operatorname{am}\left(\frac{x}{n}\right)$ par $\sin \operatorname{am}(x)$. Je me borne ici à la question de la résolution par radicaux ; plus tard je ferai, au même point de vue, l'étude des équations modulaires, et je montrerai comment les théorèmes de M. Puiseux conduisent à effectuer l'abaissement de ces équations dans les cas annotés par Galois, dont les principes serviront d'ailleurs de base à tout ce que nous allons dire.

${ }^{13} \mathrm{M}$. Puiseux a non seulement ajouté de nouveaux développements et des perfectionnements nouveaux à la théorie des intégrales curvilignes des fonctions algébriques, mais, de plus, il a mis en évidence, avec beaucoup de sagacité, les lois suivant lesquelles les diverses valeurs d'une fonction algébrique se trouvent échangées entre elles quand la courbe qui dirige l'intégration tourne autour de l'un des points qu'il nomme points principaux ; enfin, il est parvenu à déterminer généralement le nombre de valeurs distinctes et le nombre de périodes de certaines intégrales curvilignes, qui sont relatives à une classe très étendue de fonctions algébriques, et qui comprennent comme cas particuliers les intégrales elliptiques et abéliennes.

${ }^{14}$ Joseph Bertrand (1822-1900) taught mathematics and physics at Lycée Saint-Louis, École Polytechnique, École Normale Supérieure and then Collège de France. His name is attached to the "Bertrand series" in analysis and to the "Bertrand postulate" in number theory. He became member of the Académie des Sciences, in 1856, as the successor of Charles Sturm. He was the secretary ("secrétaire perpétuel") of the mathematical section of the Academy from 1874 until his death, after which Darboux became the secretary. This explains the fact that Bertrand wrote several eulogies. Bertrand was also the brother-in-law of Hermite. Paul Appell's wife was a niece of Bertrand and of Hermite and a cousin of Émile Picard.

${ }^{15}$ Charles-François Sturm (1803-1855) whose name is associated with the Sturm-Liouville principle on linear order-two differential equations with a parameter, was one of Puiseux's teachers at the Collège Rollin in Paris, which Puiseux enrolled in 1834.

${ }^{16} \mathrm{Ch}$. Sturm, notre maître bienveillant à tous, mais fier surtout de son élève du collège Rollin, m'aborda un jour par cette question que personne avant Puiseux ne s'était proposée: "Si vous 
The relation of the work of Puiseux with the notion of Riemann surface has not been sufficiently emphasized. Riemann defined these surfaces as ramified coverings of the plane (more precisely, of the Riemann sphere). The work of Puiseux on algebraic functions, interpreted from a topological point of view, contains in essence the combinatorics of such a surface, giving a description of how its sheets are permuted above a ramification point, and establishing the precise relation between this sheet permutation and the nature of the singularities of the algebraic equation. At the same time, Puiseux's work makes the relation with group theory. At the expense of being anachronical, let us mention that the theory of Puiseux expresses the so-called monodromy homomorphism from the fundamental group of the Riemann sphere with a finite set deleted (the singular set of the algebraic equation) into the permutation group on $d$ symbols. The books on the history of nineteenth-century complex analysis hardly mention Puiseux. Gray writes in [34] p. 193: "although we know from Laugwitz [45] that Riemann had read Cauchy's report on Puiseux's memoir by December 1851 it seems unlikely that Riemann had anything to learn from Puiseux by the time he was writing his doctoral thesis."

The work of Puiseux was thoroughly used in several French treatises and dissertations on complex analysis and Riemann surfaces in a period that lasted more than 50 years after the publication of this work. We refer the reader to Chapter 8 of the present volume [51].

In the next section, we give a summary of some of the tools introduced by Cauchy that were available to Puiseux. Riemann had the same tools at his disposal.

\section{Cauchy and his work on Functions of a COMPlex Variable}

When Riemann started working on his doctoral dissertation, functions of a complex variable were already studied by various authors. In particular, such functions were considered by Euler in his 1748 treatise Introductio in analysin infinitorum [29]. In 1777, Euler, in a memoir on geographical maps [31], uses complex numbers in his study of maps from the sphere to the complex plane. See also [25] for a commentary on that memoir. More importantly, by the time Riemann started his study of such functions, Cauchy had introduced several of the tools that were needed for the development of the theory of Riemann surfaces. In particular, in a series of articles he published in the 1830s and the 1840s, Cauchy studied line integrals in the complex domain and their dependence of homotopy classes of paths. This inaugurated the use of topological methods in the study of functions of a complex variable. ${ }^{17}$ Riemann, who knew the importance of Cauchy's work, was certainly following his publications. Klein, who was probably the most enthusiastic representative of Riemann, in his essay Riemann and his significance for the development of modern mathematics [42] (1895), recalls that the foundations of the theory of functions of a complex variable are due to Cauchy. He writes (p. 168):

The founder of this theory is the great French mathematician Cauchy; but only later, in Germany, did this theory assume its modern aspect which has made it the central point of our present views of mathematics. This was the result of the simultaneous efforts of two mathematicians

suivez le long d'un contour fermé la racine d'une équation dont un paramètre représente un point du contour, qu'obtiendrez-vous en revenant au point de départ ?" - "Je retrouverai ma racine, répondis-je sans hésiter." - "Eh bien, non ! vous ne la retrouverez pas : ce Puiseux le démontre. Il a fait un bien beau Mémoire !"

${ }^{17}$ One should remember though that the topological notions that appear in Cauchy's work (paths, homotopy, etc.) were still not rigorously defined, and that part of this theory was based on intuitive grounds. One of the earliest rigorous definitions of a path is contained in the much later Jordan's Cours d'Analyse de l'École Polytechnique, in three volumes, written between 1882 and 1887 (cf. [39], 2nd. edition, vol. 1, p. 90). 
whom we shall have to name together repeatedly, - of Riemann and Weierstrass. ${ }^{18}$

Weierstrass, who is mentioned in this passage, based on Cauchy's theory, developed the theory of functions of a complex variable in a way different from that of Riemann. He is known for a multitude of interesting works related to the theory of functions. To him is attributed the definition of an analytic function of a complex variable using convergent power series, ${ }^{19}$ which he developed around the year 1841 in a work which was essentially unpublished. ${ }^{20}$ This led him to a concept of Riemann surface using the principle of analytic continuation.

One of the facts that emanates from an analysis of Cauchy's work is that although he had most of his ideas early in his career, the fact that his results became precise and rigorous was progressive. Before our exposition of Cauchy's work, we shall say a few words on his life.

Cauchy was born in the year of the French revolution. He belonged to a family who escaped Paris during the revolution and had to remain discreet during the so-called Terror regime which followed it. Later, and due to a sequence of political events, Cauchy had to leave his country several times.

Like Euler and Riemann, Cauchy received his education at home, from his father. ${ }^{21}$ Laplace and Lagrange were family friends, and they encouraged Cauchy's father in the education of his son. Like Euler and Riemann, Cauchy was a devout Christian, and this had some effect on his relation with others, in particular, with Puiseux and Hermite who shared the same faith and with whom he had excellent relations, but others considered Cauchy's extreme religiousness problematic. Cauchy founded several charities, in particular the famous Euvre d'Orient, which still operates today. Valson, in his Vie et travaux du Baron Cauchy [72], writes that "Cauchy was par excellence a man of charities. For them he never bargained his time and effort." The list of mathematicians who were openly hostile to him includes Poinsot, Abel, Poisson, Fourier and there are others. We also learn from his biographers that Cauchy was often sick and had a depressive character. In a letter to Holmboë, dated October 24, 1826, the young Abel, who was visiting Paris, writes: "Cauchy is crazy and it is impossible to deal with him." In the same letter, Abel writes about Cauchy that he is extremely Catholic and bigoted, which Abel finds strange for a mathematician. He adds about him: "he is the only one actively working on pure mathematics. Poisson, Fourier, Ampère, etc. work exclusively on magnetism and other parts of physics." 22 (The text of the letter is contained in [1] p. 45-49.)

\footnotetext{
${ }^{18}$ Klein writes in a footnote: "In the text I refrained from mentioning Gauss, who being in advance of his time in this and in other fields, anticipated many discoveries without publishing what he had found. It is very remarkable that in the papers of Gauss we find occasional glimpses of methods in the theory of functions which are completely in line with the later methods of Riemann, as if unconsciously a transfer of leading ideas has taken place from the older to the younger mathematician."

${ }^{19}$ Lagrange defined complex functions using power series, but for him the notion of convergence was a secondary issue.

${ }^{20}$ Weierstrass, at that time was working in isolation, as a high-school teacher.

${ }^{21}$ In one of his writings, quoted by Bertrand [4] p. 187, Cauchy says: "If I know something, it is only through the care of my father." [Si je sais quelque chose, c'est uniquement à cause des soins que mon père a pris de moi.

${ }^{22}$ Picard, in his historical survey [54] (p. 15) describes this epoch, saying that one must not profess opinions which are too much systematic, on this parallel between pure theory and applications, like, he says, Laplace, Fourier, Poisson and the brilliant French school of mathematical physics of the beginning of the nineteenth century. "For them, he says, pure analysis was only the instrument, and Fourier, when he announced to the Academy of sciences the works of Jacobi, said that natural philosophy must be the main object of meditation of geometers." Picard says that such an exclusiveness would mean ignoring the philosophical and artistic value of mathematics.
} 
Between 1816 and 1830, Cauchy lectured regularly on analysis in Paris, at the École Polytechnique, at the Collège de France and at the Faculté des Sciences. Like Euler, Cauchy had a very close relation with his students. Valson, in [72] p. 253 of Vol. I, describes this relation:

His position of professor did not offer only the satisfaction of that feeling of generous expansion which led him to be in intimate connection with the young men of the schools he liked, whom he admitted into his study like in a lounge, with whom he was used to converse informally as a friend rather than as a master. ${ }^{23}$

Unlike Riemann and Puiseux, Cauchy was very prolific in terms of volume of writings. In this respect, he was also close to Euler. His list of publications includes more than 800 articles, and his collected works edition consists of 28 large volumes, whose publication took almost a century (1882-1974). Cauchy used to publish quickly, and it is rather common knowledge that he made mistakes which for us today seem trivial. For instance, it is considered that he thought he proved that a function of several variables is continuous provided it is continuous separately in each variable (Cours d'analyse (1821), [10] p. 37-38; Euvres, Série II, 3, p. 45-47). ${ }^{24}$ Cauchy also "proved" that a convergent series of continuous functions can be integrated term by term ([12] p. 157; (Euvres, Série 2, t. 4, p. 237-238). Chebyshev, who had a lot of respect for French mathematicians, and in particular for Cauchy, pointed out some mistakes of the latter. In one of his first papers, written in 1844, whose title is Note sur la convergence de la série de Taylor [26], he writes, after he proves a theorem concerning Taylor expansions of functions: "This theorem is only a simple conclusion of the remarkable discoveries of Mr. Cauchy; but in part, it is contrary to the rule for convergence of series that was given by this famous geometer," and he states the rule: ${ }^{25}$

If $x$ denotes a real or imaginary variable, a real or complex function of $x$ can be expanded into increasing powers of $x$ provided the value of the modulus of $x$ stays less than the smallest value for which the function or its derivative stop being finite and continuous.

Chebyshev declares that it seems that the inadequacy of this rule comes from the fact that Cauchy assumed that a definite integral may be expanded as a convergent series when the differential between the two limits of integration may be expanded as a convergent sequence. Chebyshev says that "this happens only in particular cases."

Some mathematicians argued however that Cauchy's so-called errors are in fact correct theorems when interpreted in the right setting, using his own concepts. For instance, and especially in the first period of his mathematical works, when Cauchy considers a functions, he means analytical expressions in the sense of Euler where the existence of a derivative follows from the assumptions; see e.g. [46] and [33]. We recall incidentally that there are also gaps and mistakes in some of Riemann's works, ${ }^{26}$ and there are also gaps and inconsistencies in the works of several other

\footnotetext{
${ }^{23}$ Les fonctions de professeur ne lui offraient pas seulement la satisfaction de ce sentiment d'expansion généreuse qui le portait à se mettre en communication intime avec les jeunes gens des écoles qu'il aimait, qu'il admettait dans son cabinet de travail comme dans son salon, avec lesquels il s'entretenait familièrement en ami plutôt qu'en maître.

${ }^{24}$ The first definition of a continuous function of two variables, in the sense we intend it today, using a Euclidean norm on the plane, was given by Darboux in 1872, [28].

${ }^{25}$ Cauchy's Exercices d'Analyse et de Physique Mathématique, Tome I, p. 29

${ }^{26}$ For instance, Riemann "proved" in a course he gave on complex variables that if a series of functions is convergent, then one can integrate it term by term; cf. [27] p. 13, where Riemann's proof is analyzed.
} 
great mathematicians. Fortunately, mathematicians are not evaluated by their mistakes, but only by their achievements. Mentioning the mistakes does not undervalue their work. Sometimes, on the contrary, it shows how subtle was the new material they were working with, even though today their mistakes seem obvious. Picard, in one of his famous historical talks that he gave in the United States [54], says (p. 5 ) that "error is sometimes useful, and in epochs of real creativity, an incomplete or approximate truth may be more productive than the same truth accompanied by the necessary restrictions." ${ }^{27}$ He gives the examples of Newton and Leibniz, saying that if they knew that there exist continuous function with no derivative, differential calculus would not have been born. Likewise, he says, the false ideas of Lagrange onTaylor expansions were extremely useful. One can find many examples in mathematics where gaps and mistakes led to important developments. Talking about Riemann, we mention that in 1892, Hadamard obtained the Grand Prix of the Académie des Sciences for an article on Riemann's zeta function [35], and that the subject of that contest was to fill in a gap in Riemann's work on that function. ${ }^{28}$

Cauchy submitted his first paper on definite integrals of a complex variable, the Mémoire sur les intégrales définies, in 1814 [8]. The paper is 188 pages long. Cauchy, at the time he wrote this paper, was 25, the same age at which Riemann submitted his doctoral dissertation, thirty-six years later. This was not Cauchy's first result. Cauchy found in 1805 (he was 16) a solution to a problem of Apollonius concerning a circle tangent to three circles. In 1811, he wrote two articles on polyhedra, generalizing Euler's formula, solving a rigidity problem that Lagrange asked him. Cauchy's name is now attached to this rigidity result. In Chapter 1 of the present volume [49], we comment on the work of Cauchy on polyhedra in relation with Euler's work. Legendre, in a later edition of his Éléments de géometrie, included the new proofs and the results of Cauchy on polyhedra. In 1812, Cauchy submitted a memoir on symmetric functions. In 1816, he won a prize for a contest set by the Paris Academy of Sciences concerning the propagation of water waves. The paper he presented for that competition is 300 pages long. Cauchy did these works while he was working as an engineer, at the construction site of the port of Cherbourg (between 1810 and 1813). Bertrand [4] writes that during these three years where he worked as an engineer, "Cauchy reserved several hours every day to the study of Lagrange and Laplace, but original and new ideas were perturbing him at every moment. After they stole from him his sleep, formulae were haunting him on the construction site." ${ }^{29}$ After these three years, Cauchy decided to stop working as an engineer and to come back to university.

The 1814 paper [8] of Cauchy is considered as one of his most important. It inaugurated a long series of papers on the theory of definite integrals and on complex

\footnotetext{
${ }^{27} \mathrm{On}$ peut dire que l'erreur est quelquefois utile, et que, dans les époques vraiment créatrices, une vérité incomplète ou approchée peut être plus féconde que la vérité même accompagnée des restrictions nécessaires.

${ }^{28}$ The subject of the competition was: "The determination of the number of primes smaller than a given quantity" (which is the title of Riemann's article [63]), but in the comments following the problem, it was asked to fill the gaps in Riemann's work on the zeta function. The subject of the contest was chosen by Hermite, with his friend Stieltjes in mind, who had announced in 1885 a proof of the Riemann hypothesis. In the meantime Stieltjes withdrew his "proof," and the prize went to Hadamard [35]. See the details of this story in [47], and also in Chapter 8 of the present volume [51]. Hadamard's contribution followed from the work he did in his doctoral thesis, Essai sur l'étude des fonctions données par leur développement de Taylor (Essay on the study of the functions given by their Taylor expansion), devoted to complex function theory and written under Émile Picard and Jules Tannery.

${ }^{29}$ Cauchy à Cherbourg réservait des heures réglées pour l'étude de Lagrange et de Laplace ; mais les idées originales et nouvelles le troublaient à toute heure. Après avoir usurpé sur son sommeil, les formules le poursuivaient sur les chantiers.
} 
functions, two subjects that accompanied Cauchy for the rest of his life. In this paper, Cauchy studies definite integrals in which the limits of integration are real numbers, but where the function that is integrated may be real or complex. Using the standard terminology of his epoch, Cauchy calls such a function "imaginary." Furthermore the function is allowed to become infinite at some points between the limits of integration. This led him to develop a notion of integrals he called singular. The 1814 memoir contains in an embryonic form the theory of line integrals in the complex plane which he developed later.

In two memoirs written in 1825, [13] and [14], Cauchy initiated the theory of definite integrals taken between complex values. He proved that such an integral can take more than one value, depending on the choice of a path between the (now complex) numbers $x_{0}$ and $X$. Again, this happens in particular when the function $f$ takes the value infinity at some points. Cauchy also gave a method of calculating the difference between two such values in terms of a finite number of "singular integrals." It might be important to note that one of the main reasons for which Cauchy studied integrals of functions of complex variables is that he knew that passing to complex values of the variable and using his residue calculus will also lead to results on definite integrals of functions of a real variable; see e.g. [17]. In fact, getting formulae for definite integrals was a fashionable subject at that time.

It is not possible to mention here the totality of Cauchy's later papers and books on functions of a complex variable (there are too many), and we shall say only a few words on some of them. For a comprehensive exposition of Cauchy's work on functions of a complex variable, the reader may refer to [7] and [34]. We give though a list of a few important concepts in the theory of functions that we owe to Cauchy. Our list is very far from being exhaustive, but some of the concepts we present here were crucial in the work of Riemann.

(1) The notion of path ("chemin"), in relation with functions of a complex variable, and the notion of path integral.

(2) Rigorous definitions of limits, ${ }^{30}$ of integrals (as limits of sums) and of convergence of series. In the introduction to his Cours d'analyse de l'École Royale Polytechnique [10], written in 1821, Cauchy writes:

[...] Thus, before carrying out the summation of any series, I was led to examine in what cases these series may be summed, or, in other words, what are the conditions of their convergence. And in this respect, I established general rules which I think are worth of some attention. ${ }^{31}$

In particular we owe to Cauchy the espsilon-delta and the epsilon-N definitions of limits and convergence ${ }^{32}$ as well as the notion of Cauchy sequence. In this context, Cauchy is considered as one of the main founders of the rigorous methods in analysis as we conceive them today, for what concerns convergence, infinite series, integration, etc.

(3) The notion of circle of convergence of a power series. One might note also that power series were studied by Euler and Lagrange long before Cauchy (and, in fact, the notion of power series, in Lagrange's sense was part of his definition of a function), but that it was Cauchy who considered that a power series makes sense only if it is convergent.

\footnotetext{
${ }^{30}$ Cauchy had rigorous definitions of limit and continuity, although, in some sense, it is difficult to have such rigorous definitions without a rigorous development of the notion of real number, which was done much later.

$31_{[\ldots]}$ Ainsi, avant d'effectuer la sommation d'acucune série, j'ai dû examiner dans quels cas les séries peuvent être sommées, ou, en d'autres termes, quelles sont les conditions de leur convergence ; et j'ai, à ce sujet, établi des règles générales qui me paraissent mériter quelque attention.

${ }^{32} \mathrm{On}$ this subject, besides Cauchy, one has to mention the work of Bolzano, done around the same period.
} 
(4) A theorem for local existence results for differential equations (known today as Cauchy's theorem).

(5) The definition of a holomorphic function through the partial differential equations which became known as the Cauchy-Riemann equations.

In 1851, Cauchy discovered the notion of a derivative independent of direction and he called a function with such a property "fonction monogène." 33 He showed that the real and imaginary parts of such a function must satisfy the Cauchy-Riemann equations; cf. his papers [19] and [22]. ${ }^{34}$ This was the same year (1851) that Riemann defined analytic functions using the Cauchy-Riemann equations. In fact, starting from 1831 (see [15]), Cauchy was interested in the question of when a function can be developed as a convergent power series. He introduced, rather unsuccessfully, several conditions, including the fact that the function has a continuous derivative. It was only at the beginning of the 1850 s that he came up with the condition saying that the function has a (unique) complex derivative, which is equivalent to conformality. These hesitations of Cauchy are analyzed in the thesis [52].

It is important to emphasize that even though the Cauchy-Riemann equations were known before Cauchy and Riemann, ${ }^{35}$ it is thanks to these two authors that these equations became at the forefront of the theory of functions of a complex variable, and at the same time made the connection between analysis and mathematical physics.

(6) The notion of period of a definite integral [18].

(7) The Cauchy integral formula and the calculus of residues which became known as the Cauchy formula. (An early version appears in his paper [9]).

(8) The notion of monodromy associated with a function on a given domain which attains the same value independently of the path chosen in that domain. Cauchy made the relation between this notion and that of being monogenic (having a derivative independent of direction) [23].

Cauchy, like Riemann, was also a physicist. He made important contributions to hydrodynamics, elasticity and astronomy. His name is also attached to a hypersurface in spacetime which intersects every inextensible causal curve exactly once. We mention this fact because it is related to relativity theory, a field on which the ideas of Riemann have a large impact and which is the subject of the last three chapters of the present volume.

We review now a major treatise of Cauchy on analysis, his Cours d'analyse de l'École Royale Polytechnique [10], written in 1821. This treatise was conceived as a textbook for the first-year students of the École Polytechnique, accompanying Cauchy's lectures whose aim was to present the bases of analysis in the most possible

\footnotetext{
${ }^{33}$ The Greek roots of the French word "monogène" used by Cauchy reflect the fact that this function has a unique derivative. The Greek word "monogenes" has a theological connotation. It is used in the Septuagint translation of the Bible (Hebrews 11-17), for Isaac as Abraham's "only begotten son" and in the Gospel of John (20-31) for Jesus as the "only begotten son" of God.

${ }^{34}$ It is interesting to note that in his doctoral dissertation, Riemann includes in the definition of a function of a complex variable the fact of having a derivative independent of direction. The fact that every complex function satisfies the Cauchy-Riemann equations becomes a theorem. Cf. $\S \mathrm{IV}$ of Riemann's dissertation.

${ }^{35}$ The Cauchy-Riemann equations are, in themselves, much older than Cauchy and Riemann. They already occur in d'Alembert's works on fluid dynamics, Essai d'une nouvelle théorie de la résistance des fluides, Paris, 1752. Klein, in his Development of mathematics in the 19th century ([43] p. 239) writes that "perhaps they occur even earlier."
} 
rigorous way. ${ }^{36}$ An English translation of Cauchy's Cours is available (see [11]). In fact, Cauchy published only the first part of his Cours, to which he gave the name Analyse algébrique. It is conceivable that the sequel of this treatise never appeared because of a change in the curriculum, after which Cauchy published his Résumé des leçons [12].

In his Cours, Cauchy starts with the notion of variable and constant, then he considers infinitely small quantities, the various kinds of functions of a real or complex variable, logarithms, powers, trigonometric functions, limits of functions and of sequences, convergent and divergent series, methods of solving equations, decomposition of rational functions, continuity, convergence and divergence criteria and many other items that are still taught to students today. In Chapter I, $\S 3$, Cauchy discusses functions which assign to a given value of the variable more than one value. An example is when the function is defined by a limiting procedure, and the limits are not unique. He calls such values singular values of the function. He says that such values can be obtained when the variable takes the value infinity. He writes that "the search of the singular values of functions is one of the most important and delicate questions in analysis."

Between the years 1826 and 1830, Cauchy published, on a monthly basis, a series of papers in volumes which he called Exercices de Mathématiques. Between 1840 and 1847, he published another set of four volumes, which he called Exercices d'analyse et de physique mathématique. The Exercices appeared in the form of a periodical of which Cauchy was the unique author. In several papers published in

\footnotetext{
${ }^{36}$ There is a long French tradition of Cours d'Analyse for the students of the École Polytechnique. One may mention Lagrange's Cours whose complete title is Théorie des fonctions analytiques, contenant les principes du calcul différentiel, dégagés de toute considération d'infiniment petits ou d'évanouissans, de limites ou de fluxions, et réduits à l'analyse algébrique des quantités finies (Theory of analytic functions containing the principles of differential calculus, without any consideration of infinitesimal or vanishing quantities, of limits or of fluxions, and reduced to the algebraic analysis of finite quantities), written in 1797, three years after the foundation of the École. Cauchy started to teach his course two years after Lagrange's death. One should also mention the Résumé des leçons données à l'École Royale Polytechnique sur le calcul infinitésimal (Summary of lectures on infinitesimal calculus given at the École Royale Polytechnique) (1823), a treatise which Cauchy wrote for the use of his students, after he modified his lectures because of a change in the official program. One may also mention the Résumé des cours d'analyse by Charles Hermite, in two parts (1867-1868 and 1868-1869), the Cours d'analyse de l'École Polytechnique by Charles Sturm, the Cours d'Analyse by Jacques Hadamard, the more recent Cours d'analyse by Laurent Schwartz (1967), and there are several others.
} 
the Exercices, Cauchy rewrites, corrects, improves previous results. ${ }^{37}$ In a report that Bertrand wrote on Cauchy's biography by Valson [5], he says (p. 110):

The genius of Cauchy is worthy of all our respect. But why should we refrain from recalling that the great profusion of his works, which often reduces their precision, has more than one time hidden their force? The dangerous easiness of an immediate publicity was for Cauchy a compelling temptation, and often, a pitfall. His sprit, always in motion, used to bring each week to the Academy works that were barely sketched, projects of memoirs and attempts which were sometimes unsuccessful. Even when a brilliant discovery came to crown his efforts, he used to force his reader to follow him in ways that were often infertile and which were tested and abandoned alternately without any prior notice. Let us take as an example the theory of substitutions and the number of values of a function. To whom does it owe its greatest advances? To Cauchy, without any doubt, and it is true that his name, in the history of this beautiful question, rises to a great hight above all the others. But on that theory, which owes him a lot, Cauchy composed more than twenty memoirs. Two among them are masterpieces. What can we say of the eighteen others? Nothing, except for the fact that their author is searching a new way, follows it for some time, catches a glimpse of light, tries hard pointlessly to attain it, and at the end quits, without showing any embarrassment, the avenues of the edifice which he renounces to build. ${ }^{38}$

We quote now Bertrand, from his Éloge of Cauchy ([4] p. 101):

\footnotetext{
${ }^{37}$ In his Éloge of Cauchy, Bertrand writes ([4] p. 114) about the Exercices: No mathematical publication, with whatever excellency and number of collaborators, may compete with the eight volumes of the Exercices. Avidly expected in their novelty, they are nowadays classical among the masters. No page of the Exercices is unknown to any geometer. When Cauchy had to refer to himself, he gladly referred to himself as the author of the Exercices. This title was sufficient. If some geometer today dared to publish an Exercices de mathématiques, we would be surprised by such a boldness, in the same way, and I am not exaggerating at all, as if a poet, whose name is not Lamartine or Victor Hugo, had dared to publish some Orientales or Méditations poétiques [Aucune publication mathématique, quelle que fût l'excellence et le nombre de ses collaborateurs, ne pourrait rivaliser avec les huit volumes des Excercices. Avidement attendus dans leur nouveauté, ils sont aujourd'hui classiques parmi les maîtres ; aucune page des Excercices n'est inconnue à aucun géomètre. Lorsque Cauchy avait à se citer lui-même, il se nommait volontiers : l'auteur des Exercices. Ce titre suffisait. Si un géomètre osait aujourd'hui publier des Exercices de mathématiques, on s'étonnerait d'une telle audace, tout autant, je n'exagère rien, que si un poète, sans se nommer Lamartine ou Victor Hugo, osait publier des Orientales ou des Méditations poétiques]. We note that the name Exercices for a publication was already used by Legendre, who published a famous multi-volume Exercices de calcul intégral (1811-1817) [44], a treatise whose main subject is elliptic integrals and their applications to geometry and analysis, which incidentally was one of the favorite subjects of research of Riemann.

${ }^{38}$ Le génie de Cauchy est digne de tous nos respects ; mais pourquoi d'abstenir de rappeler que la trop grande abondance de ses travaux, en diminuant souvent leur précision, en a plus d'une fois caché la force ? La dangereuse facilité d'une publicité immédiate a été pour Cauchy une tentation irrésistible et souvent un écueil. Son esprit, toujours en mouvement, apportait chaque semaine à l'Académie des travaux à peine ébauchés, des projets de Mémoire et des tentatives parfois infructueuses, et lors même qu'une brillante découverte devrait couronner ses efforts, il forçait le lecteur à le suivre dans les voies souvent stériles essayées et abandonnées tour à tour sans que rien vint l'en avertir. Prenons pour exemple la théorie des substitutions et du nombre de valeurs d'une fonction. À qui doit-elle ses plus grands progrès ? à Cauchy sans aucun doute, et il est véritable que son nom, dans l'histoire de la belle question, s'élève à une grande hauteur au-dessus de tous les autres. Mais, sur cette théorie qui lui doit tant, Cauchy a composé plus de vingt mémoires. Deux d'entre eux sont des chefs d'œuvre. Que dire des dix-huit autres ? rien, sinon que le lecteur y cherche une voie nouvelle, la suit quelque temps, entrevoit la lumière, s'efforce inutilement de l'atteindre et quitte enfin, sans marquer aucun embarras, les avenues de l'édifice qu'il renonce à construire.
} 
He was exploring new regions, whose hights were known, but nobody was able to guess the extent, the consistency, and their inexhaustible fertility. ${ }^{39}$

An Éloge funèbre is an homily in which the departed person is praised for her life and achievements, and it is natural to find in Bertrand's Éloge such laudatory words. Other people, historians of mathematics, made also very laudatory statements. We quote Bruno Belhoste, from the end of his exquisite biography of Cauchy [3]:

Thus ended the life of the greatest French mathematician of his times scarcely two years had passed since Gauss had died in Germany. A new age was now opening in the long history of mathematics, an age in which the leading figures in the mathematical sciences would be Germans. Between 1854 and 1859, Riemann, Weierstrass, and Kronecker came onto the scene on the other side of the Rhine. Meanwhile, however, in France, there was a blossoming of works on Cauchy's theory.

Laugwitz notes in his article [45] p. 80 that Cauchy's Cours d'analyse, remained for a long time the only treatise containing a complete theory of real and complex power series. He also reports that according to the Göttingen library borrowing list, Riemann, during the years 1846/47, while he was a student, borrowed this book, together with the Exercices de mathématiques and other works of Cauchy. Furthermore, in the draft for the defense of his doctoral thesis, Riemann refers to the works of Cauchy concerning the definition of an analytic function. In [48], Neuenschwander adds the following:

Riemann was suitable, as no other German mathematician was, to effect the first synthesis of the "French" and the "German" approaches in function theory. In his introductory lectures on complex function theory (cf. [67, 68, 69]; 1861), Riemann dealt with the Cauchy Integral Formulae, the operations on infinite series, the power series expansion, the Laurent series, the analytic continuation by power series, the argument principle, the product representation of an entire function with arbitrarily prescribed zeros, the evaluation of definite integrals by residues, etc., besides the subjects known from his published papers.

Riemann does not mention Cauchy in his doctoral dissertation [60]. It is not sure that Riemann, even though he borrowed from the library Cauchy's work, really read them. It is possible that he only skimmed them and reconstructed the theory on his own. Riemann however mentions Cauchy's name twice in his paper on Abelian functions [62], at the end of $\S 2$ and in $\S 6$, for a result on the expansion of a function in power series, but he adds, both times, that the result may also be proved using Fourier series. Riemann also mentions Cauchy's work three times in his Habilitation memoir on trigonometric functions [61]. The first time is in $\S 2$, in the historical part of his paper, where Riemann quotes a result where Cauchy was mistaken, and which he says, can be proved using Fourier series. ${ }^{40}$ The second time is in $\S 3$ of this memoir, where Riemann says that Cauchy's attempt to prove the convergence of a certain series is unsuccessful. The third time is in $\S 4$, where Riemann introduces his famous theory of integration. He criticizes again Cauchy's attempts to develop a general concept of definite integral. It is possible that Riemann was disturbed by Cauchy's mistakes and for this reason he was not so much inclined to quote him. Cauchy was also hardly quoted by the Germans during the same period. On the contrary, Cauchy was very generous in quoting others. Freudenthal writes his biography [32]:

\footnotetext{
${ }^{39} \mathrm{Il}$ explorait des régions nouvelles, on savait à quelle hauteur : nul n'en pouvait deviner l'étendue, la consistance et l'inépuisable fécondité.

${ }^{40}$ Riemann adds that it was Dirichlet who showed Cauchy's mistake.
} 
Of all the mathematicians of his period he is the most careful in quoting others. His reports on his own discoveries have a remarkably naïve freshness because he never forgot to sum up what he owed to others. If Cauchy were found in error, he candidly admitted his mistake.

We elaborate on the relation between the way Riemann's work on Riemann surfaces was received by the French school in Chapter 8 of the present volume [51]. Hermite, in the introduction to the treatise Théorie des fonctions algébriques et de leurs intégrales (Theory of algebraic functions and their integrals) by Appell and Goursat [2], published in 1895, makes a summary of the influence of the ideas of Puiseux, 44 years after their appearence. He writes the following:

The Memoir on algebraic functions by Puiseux, published in $1854,{ }^{41}$ opened the research ground which led to the great mathematical discoveries of our epoch. These discoveries gave the science of calculus necessary and fruitful principles which were missing until that time. They replaced the notion of function, which was still obscure and incomplete, by a precise conception which transformed analysis by giving it a new basis. Puiseux is the first who shed complete light onto the insufficiency and the defect of the point of view where we represent, in the same way as polynomials and rational fractions, the algebraic irrationals and all the quantities in infinite number which have their origin in integral calculus. Following the path of Cauchy, considering the succession of imaginary values, the paths described simultaneously by the variable and the roots of an equation, the eminent geometer highlighted, in its essential character, their analytic nature. He discovered the role of critical points, and the circumstances of the exchange of the initial values of the roots, when the variable returns to its starting point, describing a closed loop containing one or several of these roots. He resumed the consequences of these results in the study of the integrals of algebraic differentials. He noticed that the various integration paths give rise to multiple determinations, which led him to the origin - which till then was completely hidden - of the periodicity of circular functions, of elliptic functions, and of the multi-variable transcendants defined by Jacobi as inverse functions of hyperelliptic integrals. ${ }^{42}$

\section{UNIFORMIZATION AGAIN}

In the previous sections, we used the word "uniformization" in the original sense intended by Riemann, as finding a ground space on which a multi-valued function

\footnotetext{
${ }^{41}$ The year should be 1851 .

${ }^{42}$ Le mémoire de Puiseux sur les fonctions algébriques, publié en 1854, a ouvert le champ de recherches qui a conduit aux grandes découvertes mathématiques de notre époque. Ces découvertes ont donné à la science du calcul des principes nécessaires et féconds qui, jusqu'alors, lui avaient manqué; elles ont remplacé la notion de fonction, restée obscure et incomplète, par une conception précise qui a transformé l'analyse en lui donnant de nouvelles bases. Puiseux a le premier mis en lumière l'insuffisance et le défaut de ce point de vue où l'on se représente, à l'image des polynômes et des fractions rationnelles, les irrationnelles algébriques et toutes les quantités en nombre infini qui ont leur origine dans le calcul intégral. En suivant la voie de Cauchy, en considérant la succession des valeurs imaginaires, les chemins décrits simultanément par la variable et les racines d'une équation, l'éminent géomètre a fait connaître, dans ses caractères essentiels, leur nature analytique. Il a découvert le rôle des points critiques, et les circonstances de l'échange des valeurs initiales des racines, lorsque la variable revient à son point de départ, en décrivant un contour fermé comprenant un ou plusieurs de ces points. Il a poursuivi les conséquences de ces résultats dans l'étude des intégrales de différentielles algébriques. Il a reconnu que les divers chemins d'intégration donnent naissance à des déterminations multiples, ce qui l'a conduit à l'origine, jusqu'alors restée entièrement cachée, de la périodicité des fonctions circulaires, des fonctions elliptiques, des transcendantes à plusieurs variables définies par Jacobi comme fonctions inverses des intégrales hyperelliptiques.
} 
defined by an algebraic equation becomes uniform (that is, single-valued). We showed that the question of uniformization, in this sense, was a major factor in the development of the theory of Riemann surfaces. Later on, the word uniformization acquired several new meanings, albeit variations on the original one. One of the alternative formulations of the uniformization problem is the following: Given an algebraic equation $f(z, w)=0$ as in $\S 2$ above, to find two single-valued functions $z(t)$ and $w(t)$ of a variable $t$ such that the equation $f(z(t), w(t))=0$ is satisfied. This is the form in which Poincaré used this word. Besides his formulation of the problem, Poincaré introduced automorphic functions in the study of uniformization. In an 1882 Comptes Rendus note [55], he announces a result saying that for any algebraic curve of genus $\geq 2$ defined by an algebraic equation $f(z, w)=0$ there exists two Fuchsian functions $F(u)$ and $G(u)$ satisfying $f(F(u), G(u))=0$. One year later, in his paper [56], he stated a general uniformization theorem, in which the reference to algebraic functions disappeared:

Let $y$ be an analytic function of $x$, which is non-uniform. We can always

find a variable $z$ such that $x$ and $y$ are uniform functions of $z \cdot{ }^{43}$

This is the general form of the uniformization problem. It took several years for Poincaré to provide a proof of this theorem. The attempts to prove this general statement made the subject of uniformization, for several decades, a vast subject of research. Whereas from the French side only one name comes to the forefront: Poincaré, on the German side, a multitude of prominent mathematicians were involved in this uniformization program (Christoffel, Hilbert, Klein, Koebe, Osgood, Schwarz, and there are others). It is not our aim here to enter into this immense research ground, but we would like to recall Hilbert's Problem 22, a problem concerning specifically this general uniformization. This is one of the problems that Hilbert presented in his lecture, delivered on August 1900, at the Second International Congress of Mathematicians held in Paris. The lecture is entitled The future problems of mathematics, and the problems he presented became a guide for a substantial part of the mathematical research that was conducted in the twentieth century. Several slightly different versions of Hilbert's problems were published by Hilbert after that lecture, in various journals and in several languages. Moreover, the number of problems is not the same in all these versions. The paper published in the Bulletin of the American Mathematical Society ([38], 1901) contains a commented set of twenty-three problems. Problem 22 is entitled Uniformization of analytic relations by means of automorphic functions. Hilbert presents the problem completely in the tradition of Poincaré, as the one of reducing a two-variable relation to a one-variable one, by introducing automorphic forms. In his statement of and his comments on the problem, Hilbert mentions several times Poincaré and no other mathematician, except for Picard, whom he mentions at the end of his text, when he suggests a more general uniformization problem, involving algebraic (and, more generally, analytic) equations of three or more variables. Let us review precisely Hilbert's statement:

As Poincaré was the first to prove, it is always possible to reduce any algebraic relation between two variables by the use of automorphic functions of one variable. That is, if any algebraic equation in two variables be given there can always be found for these variables two such single valued automorphic functions of a single variable that their substitution renders the given algebraic equation an identity. The generalization of this fundamental theorem to any analytic non-algebraic relations whatever between two variables has likewise been attempted with success by

\footnotetext{
${ }^{43}$ Soit $y$ une fonction analytique de $x$, non uniforme. On peut toujours trouver une variable $z$ telle que $x$ et $y$ soient fonctions uniformes de $z$.
} 
Poincaré, ${ }^{44}$ though by a way entirely different from that which served him in the special problem first mentioned. From Poincaré's proof of the possibility of reducing to uniformity an arbitrary analytic relation between two variables, however, it does not become apparent whether the resolving functions can be determined to meet certain additional conditions. Namely, it is not shown whether the two single valued functions of the one new variable can be so chosen that, while this variable traverses the regular domain of these functions, the totality of all regular points of the given analytic field are actually reached and represented. On the contrary it seems to be the case, from Poincaré's investigations, that there are beside the branch points certain others, in general infinitely many other discrete exceptional points of the analytic fields, that can be reached only by making the new variable approach certain limiting points of the function. In view of the fundamental importance of Poincaré's formulation of the question it seems to me that an elucidation and resolution of this difficulty is extremely desirable.

In conjunction with this problem comes up the problem of reducing to uniformity an algebraic or any other analytic relation among three or more complex variables - a problem which is known to be solvable in many particular cases. Toward the solution of this the recent investigations of Picard on algebraic functions of two variables are to be regarded as welcome and important preliminary studies.

The uniformization problem in its general form was solved eventually by Poincaré and Koebe. There are several modern books and articles that report on this problem and its solution. The interested reader should go through the original papers, guided by the modern reports.

Acknowlegements. - I would like to thank Vincent Alberge, Ken'ichi Ohshika and François Laudenbach for their comments on a preliminary version of this chapter.

\section{REFERENCES}

[1] N.-H. Abel, Niels-Henrik Abel : Mémorial publié à l'occasion du centenaire de sa naissance, ed. E. horst, C. Størmer, L. Sylow, (bilingual, French and Norwegian) Christiania, Brøgger, 1902.

[2] P. Appell, É. Goursat, Théorie des fonctions algébriques et de leurs intégrales : Étude des fonctions analytiques sur une surface de Riemann, Paris, Gauthier-Villars, 1895.

[3] B. Belhoste, Cauchy, 1789-1867. Un mathématicien légitimiste du XIXe siècle. Belin, Paris. Engl. translation: Augustin-Louis Cauchy: a Biography. Springer, New York 1991.

[4] J. Bertrand, Éloge de Augustin Cauchy, Académie des Sciences de Paris, lu à la séance publique du lundi 10 janvier 1898.

[5] J. Bertrand, Rapport sur "La vie et les travaux du Baron Cauchy par C.-A. Valson," Bulletin des sciences mathématiques et astronomiques 1 (1870), 105-117.

[6] J. Bertrand, Éloge de M. Victor Puiseux, lu dans la séance publique annuelle de l'Académie des sciences du 5 mai 1884, Bulletin des sciences mathématiques et astronomiques 2e série, tome 8, no. 1 (1884) 227-234.

[7] U. Bottazini and J. Gray, Hidden Harmony - Geometric Fantasies: The Rise of Complex Function Theory, Springer Verlag, New York, Heidelberg, Dordrecht, London, 2013.

[8] A.-L. Cauchy, Mémoire sur les intégrales définies (1814), Mémoires présentés par divers savants à l'Académie royale des sciences de l'Institut de France 1(1827) 611-799. In Euvres Complètes, série 1, tome I, 319-506.

[9] A.-L. Cauchy, Mémoire sur l'intégration des équations linéaires aux différentielles partielles et à coefficients constants. J. Ecole Polytechnique, 12 (1823), 511-592, Euvres Complètes, série 2, tome I, 275-357.

[10] A.-L. Cauchy, Cours d'analyse de l'École Royale Polytechnique, $1^{\text {re }}$ partie. Analyse algébrique. Imprimerie royale, Paris, 1821. CEuvres Complètes, série 2, tome III.

\footnotetext{
${ }^{44}$ [Hilbert's footnote:] Bull. Soc. Math. de France, vol. 11 (1883).
} 
[11] A.-L. Cauchy, Cauchy's Cours d'analyse: An Annotated Translation of [10] by R. E. Bradley, C. E. Sandifer, Springer Verlag, Sources and Studies in the History of Mathematics and Physical Sciences, 2009.

[12] A.-L. Cauchy, Résumé des leçons données à l'école Royale Polytechnique sur le calcul infinitésimal, tome I, Paris, 1923. CEuvres Complètes, série 2, tome IV, 5-261.

[13] A.-L. Cauchy, Mémoire sur les intégrales définies prises entre des limites imaginaires, Imprimerie Royale, Paris, 1825, CEuvres Complètes, série 2, tome XV, p. 41-89.

[14] A.-L. Cauchy, Mémoire sur les intégrales définies prises entre des limites imaginaires, Bulletin des sciences mathématiques, astronomiques, physiques et chimiques (Bulletin de Férussac), tome III, p. 214-221, 1825, Euvres Complètes, série 2, tome II, p. 57-65.

[15] A.-L. Cauchy, Sur la mécanique céleste et sur un nouveau calcul qui s'applique à un grand nombre de questions diverses, Mémoire presented to the Academy of Turin, 1831, Euvres Complètes, série 2, tome II, vol. 2, p. 158-168.

[16] A.-L. Cauchy, Sur le nombre de valeurs égales ou inégales que peut acquérir une fonction de $n$ variables indépendantes, quand on permute ces variables entre elles d'une manière quelconque, Comptes Rendus Acad. Sc. Paris, t. XVIII (15 septembre 1845), 593-607, Euvres Complètes, série 1, tome 9, p. 277-293

[17] A.-L. Cauchy, Mémoire sur les intégrales dans lesquelles la fonction sous le signe $\int$ change brusquement de valeur, Comptes Rendus Acad. Sc. Paris, t. XXIII (1846) 557-563, série I tome X, 135-143.

[18] A.-L. Cauchy, Considérations nouvelles sur les intégrales définies qui s'étendent à tous les points d'une courbe fermée, et sur celles qui sont prises entre des limites imaginaires. Comptes Rendus Acad. Sc. Paris, 23 (1846), 689-704, Euvres Complètes, série 1, tome 10, p. 153-168.

[19] A.-L. Cauchy, Sur les fonctions de variables imaginaires, Comptes Rendus Acad. Sc. Paris 32 (1851) 207-215, CEuvres Complètes, série I tome XI, 301-304.

[20] A.-L. Cauchy, Rapport sur un Mémoire présenté à l'Académie par M. Puiseux et intitulé: Recherches sur les fonctions algébriques. C. R., t. XXXII, p. 276 (25 février 1851). (Euvres Complètes, série 1, tome 11 p. 325-335

[21] A.-L. Cauchy, Rapport sur un Mémoire présenté à l'Académie par M. Puiseux, et intitulé: Nouvelles recherches sur les fonctions algébriques. C. R., t. XXXII, p. 493 (7 avril 1851). (Euvres Complètes, série 1, tome 11 p. 380-382

[22] A.-L. Cauchy, Sur les fonctions monotypiques et monogènes, Comptes Rendus Acad. Sc. Paris 32 (1851) 484-487. Euvres Complètes, série I tome XI, 376-380.

[23] A.-L. Cauchy, Mémoire sur l'application du calcul infinitésimal à la détermination des fonctions implicites. Comptes Rendus Acad. Sc. Paris 34 (1852), 265-273, Euvres Complètes, série I tome XI, 406-415.

[24] A. Cayley, On the theory of groups, as depending on the symbolic equation $\theta^{n}=1$, Philosophical Magazine, 7 (1854) 40-47, and The Collected Mathematical Papers of Arthur Cayley, Cambridge University Press, Cambridge, 1889, vol. 2, pp. 123-130.

[25] C. Charitos and I. Papadoperakis, On a theorem of Euler on mappings from the sphere to the plane. In: Essays in non-Euclidean geometry, and V. Alberge and A. Papadopoulos, European Mathematical Society, Zurich, to appear in 2018.

[26] P. L. Chebyshev, Note sur la convergence de la série de Taylor, Jour. Für die Reine and ungewandte Mathematik, B. 28, 1844, p. 279-283. Reprinted in Euvres de P. L. Tchebycheff, ed. A. Markoff and A. Sonin, Tome I, Saint-Pétersbourg, 1899, p. 9-14.

[27] P. Dugac, Problèmes de l'histoire de l'analyse mathématique au XIXème siècle. Cas de Karl Weierstrass et de Richard Dedekind, Historia Mathematica 3 (1976) No. 1, 5-19.

[28] G. Darboux, Sur un théorème relatif à la continuité des fonctions, Bull. Sci. math., 3 (1872), 307-313.

[29] L. Euler, Introductio in analysin infinitorum, first edition 1748. Opera omnia, Series 1, vol. VIII.

[30] L. Euler, Introduction to Analysis of the Infinite, English translation of [29] by J. T. Blanton, 2 vol., Springer-Verlag, New York, 1988.

[31] L. Euler, De repraesentatione superficiei sphaericae super plano, Acta Academiae Scientarum Imperialis Petropolitinae 1777, 1778, pp. 107-132, Opera Omnia: Series 1, Volume 28, pp. $248-275$

[32] H. Freudenthal, article "Cauchy," Dictionary of Scientific Biography, vol. III, Scribner, New York, 1971, 131-148.

[33] E. Giusti, Gli "errori" di Cauchy e i fondamenti dell'analisi, Boll. Stor. Sci. Mat. 4 (1984), No.2, 24-54.

[34] J. Gray, The Real and the Complex: A History of Analysis in the 19th Century, Springer Verlag, Cham, Heidelberg, New York, Dordrecht, London, 2015. 
[35] J. Hadamard, Étude sur les propriétés des fonctions entières et en particulier d'une fonction considérée par Riemann. Mémoire couronné en 1892 par l'Académie : Grand Prix des Sciences Mathématiques, J. Math. Pures Appl. Série 4, 9 (1893), 171-215.

[36] Ch. Hermite, Sur la théorie des fonctions elliptiques, Comptes Rendus Acad. Sc. Paris, 29 (1849), 594. CEuvres, t. I, p. 74.

[37] Ch. Hermite, Sur les fonctions algébriques, Comptes Rendus Acad. Sc. Paris, tome XXXII (1851) 458-461.

[38] D. Hilbert, Mathematische Probleme, Göttinger Nachrichten, 1900, pp. 253-297, reprinted in Archiv der Mathematik und Physik, 3d. ser., vol. 1 (1901) pp. 44-63 and 213-237. English version, "Mathematical problems," reprinted also in the Bull. Amer. Math. Soc. (N.S.) 37 (2000), no. 4, 407-436.

[39] C. Jordan, Cours d'analyse de l'École Polytechnique, Gauthier-Villars, Paris, 2d ed. 1893, 3d. ed. 1909.

[40] C. Jordan, Traité des substitutions et des équations algébriques. Gauthier-Villars, Paris, 1878. New edition Gauthier-Villars, Paris 1957. New edition, Gabay, Paris 1989.

[41] F. Klein, Über Riemanns Theorie der algebraischen Funktionen und ihrer Integrale, Teubner, Leipzig, 1882. English translation: On Riemann's theory of algebraic functions and their integrals; a supplement to the usual treatises. Translated from the German by Frances Hardcastle, Macmillan and Bowes, Cambridge, 1893. Reprint: New York, Dover Publications, 1963.

[42] F. Klein, Riemann und seine Bedeutung für die Entwicklung der modernen Mathematik, in F. Klein, Gesammelte mathematische Abhandlungen, Berlin: Springer-Verlag, 1923 (reprinted 1973), 3: 482-497. English translation: Riemann and his significance for the development of modern mathematics. Bull. AMS, Vo. 1 (1895) No. 5, 165-180.

[43] F. Klein, Vorlesungen über die Entwicklung der Mathematik im 19. 2 volumes, Julius Springer, Berlin, 1926. English translation by M. Ackermann: Development of mathematics in the 19th century, Math. Sci. Press, Brookline, Mass.,1979.

[44] A.-M. Legendre, Exercices de calcul intégral sue divers ordres de transcendantes et sur les quadratures, 3 volumes, Paris, Courcier, 1811-1816.

[45] D. Laugwitz, Bernhard Riemann (1826-1866), Turning points in the conception of mathematics, translated by A. Schenitzer, Birkhäuser, 1999. Reprint, 2008.

[46] D. Laugwitz, Infinitely small quantities in Cauchy's textbooks, Historia Mathematica 14 (1987), Issue 3, 258-274.

[47] V. Maz'ya and T. Shpaposhnikova, Jacques Hadamard, A universal mathematician, History of Mathematics 14, AMS \& LMS, 1998.

[48] E. Neuenschwander, Studies in the history of complex function theory. II: Interactions among the French school, Riemann, and Weierstrass. Bull. Am. Math. Soc., New Ser. 5 (1981), 87-105.

[49] A. Papadopoulos, Looking backward: Euler and Riemann, In: From Riemann to differential geometry and relativity (L. Ji, A. Papadopoulos and S. Yamada, ed.) Berlin: Springer, 2017.

[50] A. Papadopoulos, Physics in Riemann's mathematical papers, In: From Riemann to differential geometry and relativity (L. Ji, A. Papadopoulos and S. Yamada, ed.) Berlin: Springer, 2017.

[51] A. Papadopoulos, Riemann surfaces: reception by the French school, In: From Riemann to differential geometry and relativity (L. Ji, A. Papadopoulos and S. Yamada, ed.) Berlin: Springer, 2017.

[52] J. Pfeiffer, Les premiers exposés globaux de la théorie des fonctions de Cauchy, thèse de doctorat de 3e cycle, EHESS, Paris, 1978.

[53] E. Picard, La vie et l'œuvre de Jules Tannery, Académie des Sciences, lecture faite dans la séance publique annuelle du 14 décembre1925.

[54] É. Picard, Sur le Développement de l'Analyse et ses Rapports avec diverses Sciences: Conférences faites en Amérique, Paris, Gauthier-Villars, 1905.

[55] H. Poincaré, Sur les fonctions fuchsiennes, C. R. Acad. Sci. Paris, 94 (1882), 1038-1040. CEuvres II, pp. 41-43.

[56] H. Poincaré, Sur un théorème de la théorie générale des fonctions, Bull. Soc. Math. France, 11 (1883), 112-125. CEuvres IV, pp. 57-69.

[57] V.-A. Puiseux, Recherches sur les fonctions algébriques, Journal de Mathématiques Pures et Appliquées, 15 (1850) p. 365-480.

[58] V.-A. Puiseux, Nouvelles recherches sur les fonctions algébriques, Journal de Mathématiques Pures et Appliquées, 16 (1851) p. 228-240.

[59] V.-A. Puiseux, Mémoire sur l'accélération séculaire du mouvement de la lune Paris, Imprimerie Nationale, 1873, 129 p. 
[60] B. Riemann, Grundlagen für eine allgemeine Theorie der Functionen einer veränderlichen complexen Grösse, (Göttingen, 1851), [65] pp. 3-48.

[61] B. Riemann, Über die Darstellbarkeit einer Function durch eine trigonometrische Reihe (On the representability of a function by a trigonometric series)

[62] B. Riemann, Theorie der Abel'schen Functionen. Journal für die reine und angewandte Mathematik, 54 (1857), 115-155. Reprinted in his Gesammelte mathematische Werke [65], pp. 88-144.

[63] B. Riemann, Über die Anzahl der Primzahlen unter einer gegebenen Grösse, Monatsberichte der Berliner Akademie, November 1859, 671-680, Gesammelte mathematische Werke [65], pp. 145-153.

[64] B. Riemann, Beiträge zur Theorie der durch die Gauss'sche Reihe $F(\alpha, \beta, \gamma, x)$ darstellbaren Functionen. Aus dem siebenten Band der Abhandlungen der Königlichen Gesellschaft der Wissenschaften zu Göttingen (1857) 3-32.

[65] B. Riemann, Gesammelte mathematische Werke, wissenschaftlicher Nachlass und Nachträge. Nach der Ausgabe von Heinrich Weber und Richard Dedekind neu hrsgg. von Raghavan Narasimhan. (Collected mathematical works, scientific posthumous works and supplements. According to the edition by H. Weber and R. Dedekind newly edited by R. Narasimhan). Teubner Verlagsgesellschaft, Leipzig, 1862; Springer-Verlag, Berlin (1990).

[66] B. Riemann, Collected works translated into French: CEuvres mathématiques de Riemann, traduites par L. Laugel, avec une préface de M. Hermite et un discours de Félix Klein, Paris, Gauthier-Villars, 1898.

[67] B. Riemann, Theorie der Functionen complexer Variabeln. Vorlesung des Prof. Riemann. Göttingen, Sommersemester 1861; lecture notes taken by E. Abbe formerly in the possession of G. Thieme, Cod. MS: Riemann 32c, Niedersächsische Staats- und Universitätsbibliothek Göttingen.

[68] B. Riemann, Theorie complexer Functionen. Im Sommersemester 1861, 4stündig vorgetragen von B. Riemann; lecture notes taken by H. Hankel, formerly in the possession of G. Thieme, Cod. MS: Riemann 32g, Niedersächsische Staats- und Universitätsbibliothek Göttingen.

[69] B. Riemann, Theorie der Functionen einer complexen Größe. Vorgetragen von Prof. Riemann. Göttingen, Sommer 1861. Winter 1861/62. Friedrich Prym, Doctor phil.; lithographie: Friedr. Umlauft. Vind. 1865.

[70] R. Taton, Sur les relations scientifiques d'Augustin Cauchy et d'Evariste Galois. Revue d'histoire des sciences, 24 (1971) No. 2, 123-148.

[71] F. Tisserand, Notice sur Victor-Alexandre Puiseux. Bulletin des sciences mathématiques et astronomiques, Sér. 2, 8 (1884) no. 1, 234-245.

[72] C.-A. Valson, La vie et les travaux du Baron Cauchy, Gauthier-Villars, 2 volumes, 1868.

[73] H. Weyl, Die Idee der Riemannschen Fläche. B.G. Teubner, Leipzig, 1913. English translation by G. R. MacLane, The concept of a Riemann surface, Addison-Wesley, 1955.

Institut de Recherche Mathématique Avancée, CNRS et Université de Strasbourg, 7 rue René Descartes - 67084 Strasbourg Cedex, France, and Brown University, Mathematics Department, 151 Thayer Street Providence, RI 02912, USA. 